\title{
Analysis of Research Trends in Agricultural Engineering
}

\author{
Sławomir Francik \\ Department of Mechanical Engineering \\ and Agrophysics \\ Faculty o Production and Power \\ Engineering, \\ University of Agriculture \\ Krakow, Poland \\ slawomir.francik@urk.edu.pl \\ Zbigniew Ślipek \\ Department of Mechanical Engineering \\ and Agrophysics \\ Faculty o Production and Power \\ Engineering, \\ University of Agriculture \\ Krakow, Poland \\ zbigniew.slipek@urk.edu.pl
}

\author{
Jarosław Frączek \\ Department of Mechanical Engineering \\ and Agrophysics \\ Faculty o Production and Power \\ Engineering, \\ University of Agriculture \\ Krakow, Poland \\ jaroslaw.fraczek@urk.edu.pl
}

\begin{abstract}
Nowadays it is necessary to define actual global research trends in disciplines in order to determine the major research topics, discoveries and global scientific networks. The goal of the work was to determine the main topics and research trends in agricultural engineering. For this caser he method of modified bibliometric analysis was applied. Such analysis of the keywords frequency occurrence and the links between the keywords in Biosystems Engineering Journal shows that in the three analysed periods, certain keywords invariably remain dominant. These are "model", "system" or "systems", "temperature" and "water". The highest number of publications was qualified for the CIGR section: Information Technology. It can be, therefore, stated that in the recent period the most intensively developing researches were dedicated to the application of IT tools in creation various types of models, allowing to simulate and optimize agricultural processes. A majority of publications covered decision-making support (Decision Support Systems), image analysis application, and automation of agricultural processes.
\end{abstract}

Keywords - agricultural engineering, bibliometric analysis, biosystems engineering, research trends

\section{INTRODUCTION}

It is important for researchers to know the current research trends in a discipline (such as agricultural engineering) in order to decide in which direction to plan their future research. Regular analysis of research trends related to specific disciplines can help researchers publish more effectively. It is necessary to define a new global research trends that have developed in the discipline in order to determine the major research topics, discover and global knowledge networks. This necessity is emphasized by many authors of scientific publications. Bibliometric studies are widely applied in the analysis of research trends [1]-[7].
Bibliometry was introduced by Pritchard in 1969 as a method of mathematical and statistical analysis applied to books and other communication media. Citation and content analyses are now widely used bibliometric techniques. Broadus defined bibliometry as a quantitative analysis of physically published units or bibliographic units. Bibliometric techniques have many advantages. The most important is the ability to conduct quantitative analyses objectified based on the codified knowledge measurable, objectified, consistent and accessible data. Hence, bibliometrics is an effective and important tool to determine the trends of research in various fields of science [8]. Bibliometric studies include a number of quantitative and visual procedures to generalize patterns and dynamics of publications [7].

The goal of the work was to determine the main topics and research trends in agricultural engineering. The method of bibliometric analysis was applied.

In line with the CIGR (International Commission of Agricultural and Biosystems Engineering) definition, agricultural engineering “. . . has been applying scientific principles for the optimal conversion of natural resources into agricultural land, machinery, structure, processes and systems for the benefit of man.

Beside the classical agricultural engineering topics, a comparatively new research area of biosystems engineering was analysed. „Biosystems Engineering” is research in the physical sciences and engineering to understand, model, process or enhance biological systems for sustainable developments in agriculture, food, land use and the environment" [9]. 


\section{Materials and Methods}

A modified bibliometric analysis method proposed by Rizzi and Leydesdorff [10] was applied in the work. The following stages of analysis were adopted:

1. Identifying journals in the Web of Science "Agricultural Engineering" category from the Journal Citation Reports database.

2. Determining the journals which had the most significant impact on research development in the discipline of agricultural engineering.

3. Selecting one journal for further analysis and determining the length of analysis periods.

4. Uploading all publications of the selected journal in the analysed period of time and extracting bibliometric data (authors, title, year of issue, key words, additional key words, publishing house).

5. Construction and analysis of term maps (VOSviewer software).

6. Identifying the most frequently found key words for the selected journal in the analysed period of time.

7. An topic analysis of the publications which were identified with the use of the most frequently occurring key words (topic: model \& system).

One of the most widely used databases for bibliometric analysis of publications in the Web of Science (WoS), which contains articles with the highest level of quality - from magazines with a significant impact factor. Therefore, in this study the WoS database has been used as a data source [8].

All publications in the WoS: „AGRICULTURAL ENGINEERING" category were identified with the use of the tools of InCites Journal Citation Reports. The years 2000-2016 were analysed.

From among the identified journals, the journals which were indexed in the Web of Science - Core Collection (WoS-CC) database for minimum 10 years were selected for further analysis. The analysis of the change of the number of publications in a given period of time was performed on this sample.

It was assumed that to have a significant impact on the development of a given field, journals needed to be indexed in WoS-CC during the whole period or in the recent years (minimum since 2006).

Selection of one journal for further analysis was performer with the use of journal ranking in 2016 in the WoS "Agricultural Engineering" category and the topic range closely connected with the category (the journal linked to maximum two WoS categories).

Bibliometric analyses were performer with the use of the freeware, VOSviewer. This program is used for creating and graphic visualisation of bibliometric maps. VOSviewer utilized the method of ,visualization of similarities" VOS. The program allows to create maps of authors, journals etc.[11].
In this work the program was used to create maps of terms in the version of ,thermic maps".

Such maps allow for analysing concentrations in a simple way.

The key words with the highest occurrance frequency are displayed in a circles a bigger size.

The words with the lower frequency of occurance, on the other hand, have smaller font and they are presented in a smaller circles.

VOSviewer is widely used for bibliometric analyses, mainly to analyse research trends [12]-[15], but also to visualize certain fields of knowledge [16].

Identifying the most frequent key words for a given journal was also performed with the use of VOSviewer program - 14 most frequently occurring key words in each of the three analysis periods were determined. Out of the lot, only the key words occurring in each of the three periods were used for further analysis.

The next stage covered the quantitative analysis (for the 3 periods) and topics analysis (the most recent period) of publications which had been identified in the Web of Science - Core Collection database with the use of the most frequently found key words. The search was limited to the selected journal (BIOSYSTEMS ENGINEERING) and to the publications which contained two of the most frequently used key words.

The analysis of topics was performer by assigning individual publications on agricultural engineering research topics (agricultural engineering) to one of 7 CIGR Technical Sections:

Section I: Land and Water,

Section II: Structures \& Environment,

Section. III: Plant Production,

Section. IV: Energy in Agriculture,

Section. V: System Management,

Section. VI: Bioprocesses,

Section VII: Information Technology

Assigning followed the analysis of the publication contents based on abstracts.

\section{RESULTS}

A total of 18 journals can be found in the WoS 'AGRICULTURAL ENGINEERING' category in the years 2000-2016. The journals selected for further analysis were those which were indexed in the WoS - Core Collection database for minimum 10 years. For thus selected 7 journals, the number of publications in the analysed years was determined. The analyzes show that 3 journals (Bioresource Technology, Biomass \& Bioenergy, and Industrial Crops And Products) show a significant increase in the number of publications. The other journals in the analysed period of time showed an even distribution of the number of publications. In total, the presented journals 
published 31402 publications in the researched period.

The journals with the highest rank (the highest citation index / impact factor) had the most significant impact on the research development in the field of Agricultural Engineering. Those were the journals which in the year 2016 belonged to the Q1 quartile (according to JCR): Bioresource Technology (position 1/14), Biomass \& Bioenergy (position 2/14), Industrial Crops and Products (position 3/14) and to the Q2 quartile: Biosystems Engineering (position 4/14).

The Biosystems Engineering journal (position no. 4 in the ranking) was selected for further analyses. The journal was categorized as WoS 'AGRICULTURAL ENGINEERING' and 'AGRICULTURE, MULTIDISCIPLINARY'. The journals with the positions 1-3 in the JCR ranking are classified in a higher number of categories. Their range of topics is, thus, very wide. Publications in the Biosystems Engineering journal are the most homogenous with regard to the presented topics.

According to the information on the journal web site," Biosystems Engineering publishes research in engineering and the physical sciences that represent advances in understanding or modelling of the performance of biological systems for sustainable developments in land use and the environment, agriculture and amenity, bioproduction processes and the food chain. The subject matter of the journal reflects the wide range and interdisciplinary nature of research in engineering for biological systems."

The Biosystems Engineering journal has been indexed in the WoS database since 2002 (Formerly known as Journal of Agricultural Engineering Research).

For this reason, it was decided to split three 5-year research periods:

- $\quad$ period I 2002-2006,

- $\quad$ period II 2007-2011,

- $\quad$ and period III 2012-2016.

In the analysed periods of time the Biosystems Engineering journal published a total of 2354 articles which were distributed over the time periods as follows: period I - 751, period II - 807, period III - 796. The bibliometric data was extracted for all the publications (Title, Abstract, Author Key Words, Key Words Plus, year of publishing).

In the next stage, the most frequently occurring key words were determined for the analysed periods. For each period the analysis of all key words (Author Keywords, KeyWords Plus) was performed. The analysis was limited to the key words which occurred minimum 5 times. Results of the simulations are presented in Fig. 1.

In Fig. 1 maps of terms (key words) for the three analysed periods are presented.

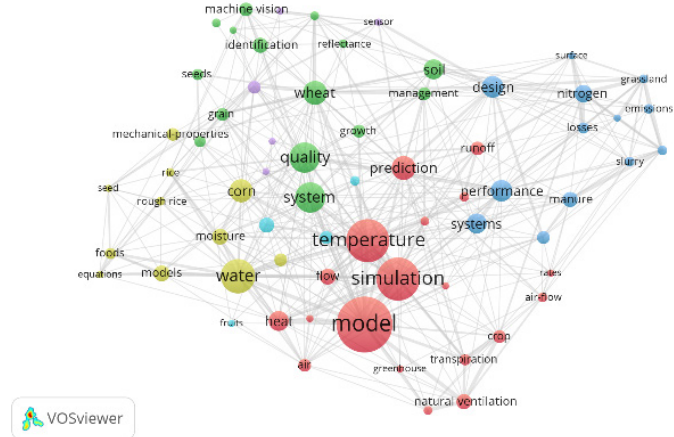

a)

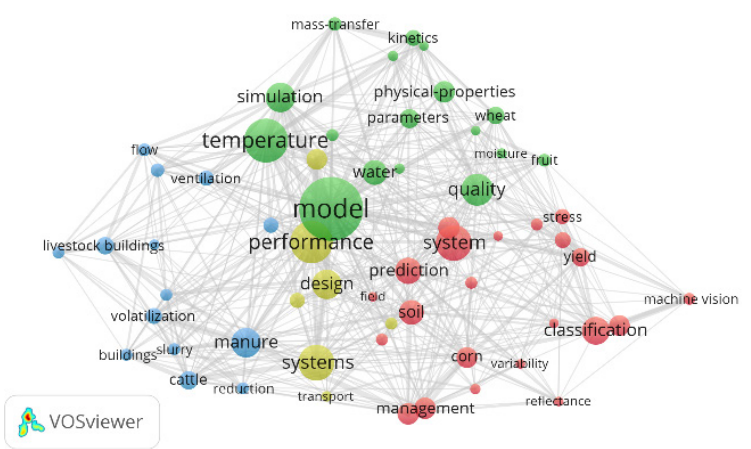

b)

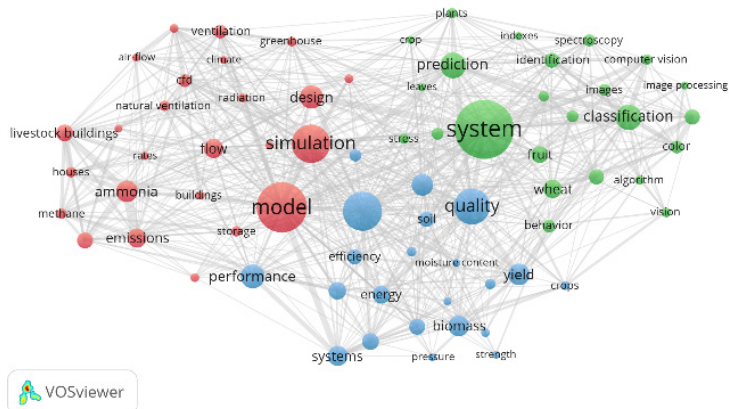

c)

Fig. 1. Set of term maps for the analysed periods: a) period I b) period II c) period III.

In selected periods can be observed several groups around the most frequently used keywords, which is the evidence of the subject-matter linkages between the key words. The main topics in the first period were: "model", "simulation", "temperature", "system", "quality", "prediction", "wheat", "water" and "design". The main topics in the second period were: "model", "temperature", "simulation", "performance”, "system”, “quality”, "prediction", "classification", "management", "manure", "physical properties" and "soil". In the last period the main topics were: "model", "system", "simulation", “design", classification”, "prediction", “quality”, "ammonia”, "emission", "livestock buildings" and "biomass". Change in the interest of researchers from the study of physical properties, prediction, simulation, quality of biological raw materials, classifications, fertilizers, soil and ending with the emission of greenhouse gases. 
Then, the most frequently used key words in the analysed periods were listed (Table 1). It can be observed that key words are repeated in the analysed periods but there are changes in their rank (the frequency of use changes). The key words which occur in all the three periods were selected for further analyses. They are shaded in the table of results.

TABLE I. LIST OF THE MOST FREQUENTLY USED KEY WORDS IN THE ANALYSED PERIODS

\begin{tabular}{|c|c|c|}
\hline Period $\mathbf{1}$ & Period $\mathbf{2}$ & Period $\mathbf{3}$ \\
\hline MODEL & MODEL & SYSTEM \\
\hline TEMPERATURE & TEMPERATURE & MODEL \\
\hline SIMULATION & PERFORMANCE & TEMPERATURE \\
\hline WATER & SYSTEMS & SIMULATION \\
\hline QUALITY & SYSTEM & QUALITY \\
\hline SYSTEM & QUALITY & PREDICTION \\
\hline PREDICTION & MANURE & CLASSIFICATION \\
\hline WHEAT & SIMULATION & PERFORMANCE \\
\hline CORN & DESIGN & DESIGN \\
\hline PERFORMANCE & CLASSIFICATION & AMMONIA \\
\hline DESIGN & PREDICTION & YIELD \\
\hline HEAT & SOIL & GROWTH \\
\hline SYSTEMS & WATER & BIOMASS \\
\hline SOIL & NITROGEN & SYSTEMS \\
\hline
\end{tabular}

In the next stage, a series of searches was performed in the Web of Science - Core Collection database with regard to the selected key words and separately for all the 3 periods. The search was limited to the category of WoS AGRICULTURAL ENGINEERING and to the selected journal (BIOSYSTEMS ENGINEERING).

TABLE II. LISTING OF THE NUMBER OF IDENTIFIED JOURNALS WITH REGARD TO THE NUMBER OF SEARCHED WORDS IN THE PERIOD I/ II / III

\begin{tabular}{|c|c|c|c|c|c|c|}
\hline $\begin{array}{c}\text { searche } \\
\text { words }\end{array}$ & $\begin{array}{c}1 . \\
+T E M\end{array}$ & $\begin{array}{c}1.2 . \\
+S I M\end{array}$ & $\begin{array}{c}1.3 . \\
+Q U A\end{array}$ & $\begin{array}{c}1.4 . \\
+P E R\end{array}$ & $\begin{array}{c}1.5 . \\
+D E S\end{array}$ & $\begin{array}{c}1.6 . \\
+P R E\end{array}$ \\
\hline $\begin{array}{c}1 . \\
T E M\end{array}$ & \multirow[t]{2}{*}{$\begin{array}{l}39 / \\
36 / \\
37\end{array}$} & $\begin{array}{l}15 / \\
15 / \\
15\end{array}$ & $\begin{array}{l}3 / \\
7 / \\
11\end{array}$ & $\begin{array}{c}6 / \\
16 / \\
10\end{array}$ & $\begin{array}{c}8 / \\
14 / \\
14\end{array}$ & $\begin{array}{c}10 / \\
6 / \\
10\end{array}$ \\
\hline $\begin{array}{c}2 . \\
S I M\end{array}$ & & $\begin{array}{c}47 / \\
42 / \\
54\end{array}$ & $\begin{array}{l}4 / \\
5 / \\
11\end{array}$ & $\begin{array}{c}12 / 15 / \\
10\end{array}$ & $\begin{array}{c}13 / 14 / \\
20\end{array}$ & $\begin{array}{c}14 / \\
8 / \\
10\end{array}$ \\
\hline $\begin{array}{c}3 . \\
Q U A\end{array}$ & & & $\begin{array}{l}10 / \\
20 / \\
42\end{array}$ & $\begin{array}{l}2 / \\
3 / \\
10\end{array}$ & $\begin{array}{l}0 / \\
5 / \\
18\end{array}$ & $\begin{array}{l}4 / \\
7 / \\
10\end{array}$ \\
\hline $\begin{array}{c}4 . \\
P E R\end{array}$ & & & & $\begin{array}{c}29 / \\
43 / \\
52\end{array}$ & $\begin{array}{c}11 / 16 / \\
19\end{array}$ & $\begin{array}{c}5 / \\
10 / \\
10\end{array}$ \\
\hline $\begin{array}{c}5 . \\
D E S\end{array}$ & & & & & $\begin{array}{c}38 / 48 / \\
57\end{array}$ & $\begin{array}{c}0 / \\
11 / \\
9\end{array}$ \\
\hline $\begin{array}{c}6 . \\
P R E\end{array}$ & & & & & & $\begin{array}{c}26 / 34 \\
36\end{array}$ \\
\hline $\begin{array}{r}\text { Leg } \\
\text { QUA }\end{array}$ & $\begin{array}{l}\text { d: TEM } \\
\text { UALIT }\end{array}$ & $\begin{array}{l}\text { EMPE } \\
\text { PER - } \\
\text { PRE - }\end{array}$ & $\begin{array}{l}\text { ITURE } \\
\text { RFORI } \\
\text { REDIC }\end{array}$ & $\begin{array}{l}\text { IM - SI } \\
\text { INCE, D } \\
\text { ON }\end{array}$ & $\begin{array}{l}\text { IULATI } \\
\text { ES - DES }\end{array}$ & $\begin{array}{l}\text { N, } \\
\text { GN, }\end{array}$ \\
\hline
\end{tabular}

The numbers of publications meeting the search criteria (different configurations of key words) are presented in Table 2. The criteria always included the words: "model" and "system". The highest number of publications (143 articles) was obtained for the two key word configurations: "model" AND "system" AND "simulation" $(143=47+42+54)$, „model” AND ,system” AND ,design” $(143=38+48+57)$.

Result of the topic analysis of publications in the third period (2012-2016) :

\section{CIGR Technical Section I - Land \& Water :}

\# irrigation systems:

- technical solutions in irrigation systems

- modeling and optimization of irrigation

- other subjects: assessing water saving at farm, modeling the impact of climate change on irrigation systems, modeling the embodied energy for irrigation systems

\section{\# study of soil physical and chemical properties}

CIGR Technical Section II - Structures \& Environment :

\# modeling and optimization ventilation system

- microclimate in livestock buildings

- designing forced air circulation system for plant factories

\# ammonia, greenhouse gas and odour emissions from livestock buildings and greenhouses:

- modeling and optimization

- emission measurement (pig production, cattle farms, greenhouses)

\# other topics: radiometric properties of materials for livestock buildings

\section{CIGR Technical Section III - Plant Production:}

\section{\# agricultural machines investigation:}

- measurement of processes parameters (disc harrow, tillage machines, combine harvester, seeder, orchard sprayers, tractor rollover)

- technical solutions in plant production systems (tillage machines, machine prototype for non-chemical weed control, semiochemical devices for pest management)

\# modeling and optimization operations in plant production:

- crop harvesting and transport

- horticulture (rose cultivation, grape harvest, sweet cherry picking

\# other topics: water requirements for plants, detection of plant nutrition level, weed control, detection of virusinfected seeds, canopy cover measurement in an onion crop, - modeling of yield maps

CIGR Technical Section IV - Energy in Agriculture: \# biomass

- measurement of biomass parameters: moisture 
content, diameters of stems

- optimisation and investment analysis: comparing of two different biomass energy exploitation systems (domestic pellet boilers, centralised co-generation unit)

$$
\text { \# energy savings }
$$

CIGR Technical Section V - System Management: \# food and grain supply chain management

\# costs analysis for machine systems and technical infrastructure

\section{\# agricultural operations planning}

\section{CIGR Technical Section VI - Bioprocesses:}

\section{\# aeration, drying and storage}

- postharvest quality of fresh fruit and vegetables

- modeling, simulation and optimization of air distribution in grain storage bins

- modeling and simulation of seed drying process,

- heat transport models

\# disinfesting postharvest fresh and stored products

\# other topics: evapotranspiration estimating techniques (agricultural crops, banana plantation, processing tomato crop), chemical oxygen demand

CIGR Technical Section VII - Information Technology:

\# image analysis

- animal production (pigs, cows, chickens),

- plant production (apples, oil palm, vegetables, citrus)

\# 3D models creating

- trees and orchard modeling based on LiDAR system

\# Decision Support Systems:

- web-based DSSs: pest management, crop production, biomass production

- DSSs for: operational planning machine activities, pig production chain

\section{\# Prediction and forecasting system}

- airborne spread of livestock infectious disease

- tools for prediction of: size and weight pigs in a herd, yield predictions in agriculture

\# autonomous tractors and machines

- automatic control and navigation

- stability evaluation of robotic agricultural on slopes

- path planning of robot for collection of eggs

\# devices for modeling and simulation

- activity of honeybees

- modeling radio propagation within orchards
- monitoring grain losses in combine harvesters

- automated monitoring tool for pest

- wireless sensor network for monitoring of temperature and oxygen concentration inside silage stacks

The last step was the topic analysis of publications in the third period (2012-2016). The review was performed for the documents which contained the words 'model*' and 'system*'. Out of 178 articles which were generated from the WoS-CC database, 35 were rejected as they did not contain the searched phrases in the title, author key words and additional key words.

In addition, 11 publications whose subject matter did not fit into the discipline Agricultural Engineering were removed.

Finally, 132 documents were analysed with regard to content. The results of topic analysis are presented in the Table 3 and Table 4. The main research topics performed in the framework of each of the research areas ( CIGR Technical Sections) were identified. Table 3 and Table 4 contain also references to the publications which pertained to a given topic.

Most of the publications (32) were related to the applications of information technology in agricultural engineering (CIGR Section: Information Technology). A smaller number of publications were related to four CIGR sections: Plant Production (27), Bioprocesses (21), Land \& Water (19) and Structures \& Environment (19). The smallest number of publications was qualified in the CIGR sections: System Management (10) and Energy in Agriculture (4).

The publications assigned to the Information Technology section discussed mainly: use of image analysis in agriculture (10), creating Decision Support Systems for agriculture (5) and introducing automatically steered machines and equipment (5). In the Plant Production section the highest number of publications discussed agricultural machines (12). In the Bioprocesses section 15 publications were dedicated to the research of aeration, drying and storage. In the Land \& Water section the highest number of publications discussed irrigation systems (16). In the Structures \& Environment section 13 publications were dedicated to the research of microclimate in inventory buildings. In the other sections there were no dominant scientific research topics.

The obtained results coincide with the activities of the Faculty of Production and Power Engineering of the University of Agriculture in Krakow, whose scientific activity is related to agricultural engineering. For example, in the range: optimization operations in plant production [17], [18] research on physical and chemical properties as well as energetic plant materials and agglomerations [19][23], waste treatment and testing of their properties [24][27], decision support systems [28], [29] and optimization of the drying process [30] and other. 


\section{CONCLUSIONS}

Summing up the results, it can be concluded that:

The results of bibliometric analyses show that the strongest influence on the research development in Agricultural Engineering was exercised by the journals with the highest JCR rank: Bioresource Technology, Biomass \& Bioenergy, Industrial Crops and Products, and Biosystems Engineering. It should be noted that the subject matter in the Biosystems Engineering journal was the one most closely connected with Agricultural Engineering.

Bibliometric analysis of the key word frequency of occurrence and the linkages between the key words in Biosystems Engineering journal (VOS Viewer program) showed that in the three analysed periods certain key words invariably remain dominant (they are placed in large circles). These are 'model', 'system' or 'systems', 'temperature' and 'water'. In different periods new most frequently occurring key words appear. Linkages between key words change, too. The analysis of the three researched periods showed that the most frequent key words have been: "model", "system", "temperature", "simulation", "quality", "performance", "design" and "prediction". It can be, therefore, stated the biggest number of scientific publications was connected with modelling of agrotechnical (biotechnological) systems and simulating their activities.

A detailed publication topic analysis of the period 2012-2016 with regard to the most frequently used topic key words (143 articles) allowed to identify the dominant research areas - research trends in agricultural engineering.

The biggest number of publications was qualified for the CIGR section: Information Technology. It can be, therefore, stated that in the recent period the most intensively developing research was dedicated to the application of IT tools for creating various types of models, allowing to simulate and optimize agricultural processes. A large number of publications covered decision-making support (Decision Support Systems), picture analysis application, and automation and robotization of agricultural processes. It can be assumed that those trends will continue in the nearest future and that the research dedicated to the application of Information Technology and mechatronics in agriculture will remain dominant.

\section{AcKNOWLEDGEMENT}

This research was financed by the Ministry of Science and Higher Education of the Republic of Poland (statutory activities DS-3600/WIPiE/2018, Faculty of Production and Power Engineering, University of Agriculture in Krakow).

\section{REFERENCES}

[1] S. Bojović, R. Matić, Z. Popović, M. Smiljanić, M. Stefanović, and V. Vidaković, "An overview of forestry journals in the period 2006-2010 as basis for ascertaining research trends," Scientometrics, vol. 98, no. 2, pp. 1331-1346, Feb. 2014.

[2] J. B. Hernández and S. Chalela, "Research Trends in the Study of ICT Based Learning Communities: A Bibliometric Analysis," EURASIA J. Math. Sci. Technol. Educ., vol. 13, no. 5, pp. 1539-1562, Dec. 2016.

[3] A. Magrí, F. Giovannini, R. Connan, G. Bridoux, and F. Béline, "Nutrient management from biogas digester effluents: a bibliometric-based analysis of publications and patents," Int. J. Environ. Sci. Technol., vol. 14, no. 8, pp. 1739-1756, Aug. 2017.

[4] E. W. Wambu, H.-Z. Fu, and Y.-S. Ho, "Characteristics and trends in global tea research: a Science Citation Index Expanded-based analysis," Int. J. Food Sci. Technol., vol. 52, no. 3, pp. 644-651, Mar. 2017.

[5] J. Wang, Z. Chen, L. Yang, and S. Xi, "Study on trends and performance of landfill research from 1999 to 2013 by using bibliometric analysis," Environ. Prog. Sustain. Energy, vol. 34, no. 5, pp. 1349-1355, Aug. 2015.

[6] X. Wu, X. Chen, F. B. Zhan, and S. Hong, "Global research trends in landslides during 1991-2014: a bibliometric analysis," Landslides, vol. 12, no. 6, pp. 1215-1226, Dec. 2015.

[7] X. Yaoyang and W. J. Boeing, "Mapping biofuel field: A bibliometric evaluation of research output," Renew. Sustain. Energy Rev., vol. 28, pp. 82-91, Dec. 2013.

[8] S. Francik et al., "Bibliometric Analysis of Multiple Critteria Decision Making in Agriculture," Tech. Sci., vol. 20, no. 1, pp. 17-30, 2017.

[9] D. Briassoulis, P. Panagakis, and E. Nikopoulos, Education and research in Biosystems engineering in Europe. ERABEE, 2009.

[10] A. Knapczyk, S. Francik, N. Pedryc, and T. Hebda, "Bibliometric analysis of research trends in engineering for rural development," in 17th International Scientific Conference Engineering for Rural Development, 2018, pp. 700-707.

[11] N. J. van Eck and L. Waltman, "Software survey: VOSviewer, a computer program for bibliometric mapping," Scientometrics, vol. 84, no. 2, pp. 523-538, Aug. 2010.

[12] F. T. Gizzi, "Worldwide trends in research on the San Andreas Fault System," Arab. J. Geosci., vol. 8, no. 12, pp. 1089310909, Dec. 2015.

[13] O. Tabatabaei-Malazy, R. Atlasi, B. Larijani, and M. Abdollahi, "Trends in publication on evidence-based antioxidative herbal medicines in management of diabetic nephropathy," J. Diabetes Metab. Disord., vol. 15, no. 1, p. 1, Dec. 2015.

[14] S. H. Zyoud, W. S. Waring, W. M. Sweileh, and S. W. AlJabi, "Global Research Trends in Lithium Toxicity from 1913 to 2015: A Bibliometric Analysis," Basic Clin. Pharmacol. Toxicol., vol. 121, no. 1, pp. 67-73, Jul. 2017.

[15] A. Watad et al., "Is autoimmunology a discipline of its own? A big data-based bibliometric and scientometric analyses," Autoimmunity, vol. 50, no. 4, pp. 269-274, May 2017.

[16] J. Zhu and W. Hua, "Visualizing the knowledge domain of sustainable development research between 1987 and 2015: a bibliometric analysis," Scientometrics, vol. 110, no. 2, pp. 893-914, Feb. 2017.

[17] T. Głąb and B. Kulig, "Effect of mulch and tillage system on soil porosity under wheat (Triticum aestivum)," Soil Tillage Res., vol. 99, no. 2, pp. 169-178, Jun. 2008.

[18] T. Głąb, "Impact of soil compaction on root development and yield of meadow-grass," Int. Agrophysics, vol. 27, no. 1, pp. 7-13, Jan. 2013.

[19] K. Kubica, M. Jewiarz, R. Kubica, and A. Szlęk, "Straw Combustion: Pilot and Laboratory Studies on a Straw-Fired 
Grate Boiler," Energy \& Fuels, vol. 30, no. 6, pp. 4405-4410, Jun. 2016.

[20] M. Niemczyk, A. Kaliszewski, M. Jewiarz, M. Wróbel, and K. Mudryk, "Productivity and biomass characteristics of selected poplar (Populus spp.) cultivars under the climatic conditions of northern Poland," Biomass and Bioenergy, vol. 111, pp. 46-51, Apr. 2018.

[21] M. Wróbel, J. Hamerska, M. Jewiarz, K. Mudryk, and M. Niemczyk, "Influence of Parameters of the Torrefaction Process on the Selected Parameters of Torrefied Woody Biomass," Springer, Cham, 2018, pp. 691-700.

[22] M. Wróbel, K. Mudryk, M. Jewiarz, S. Głowacki, and W. Tulej, "Characterization of Selected Plant Species in Terms of Energetic Use,” Springer, Cham, 2018, pp. 671-681.

[23] M. Mierzwa-Hersztek, K. Gondek, M. Jewiarz, and K. Dziedzic, "Assessment of energy parameters of biomass and biochars, leachability of heavy metals and phytotoxicity of their ashes," J. Mater. Cycles Waste Manag., Feb. 2019.

[24] B. Brzychczyk, T. Hebda, and J. Giełżecki, "Energy Characteristics of Compacted Biofuel with Stabilized Fraction of Municipal Waste," Springer, Cham, 2018, pp. 451-462.

[25] B. Brzychczyk, T. Hebda, and J. Giełżecki, "Physical and
Chemical Properties of Pellets Produced from the Stabilized Fraction of Municipal Sewage Sludge," Springer, Cham, 2018, pp. 613-622.

[26] K. Grzesik and M. Malinowski, "Life cycle assessment of refuse-derived fuel production from mixed municipal waste," Energy Sources, Part A Recover. Util. Environ. Eff., vol. 38, no. 21, pp. 3150-3157, Nov. 2016.

[27] K. Dziedzic, B. Łapczyńska-Kordon, M. Malinowski, M. Niemiec, and J. Sikora, "Impact Of Aerobic Biostabilisation And Biodrying Process Of Municipal Solid Waste On Minimisation Of Waste Deposited In Landfills," Chem. Process Eng., vol. 36, no. 4, pp. 381-394, Dec. 2015.

[28] S. Francik, N. Pedryc, A. Knapczyk, A. Wójcik, R. Francik, and B. Łapczyńska-Kordon, "Bibliometric Analysis of Multiple Critteria Decision Making in Agriculture," Tech. Sci., vol. 20, no. 1, pp. 17-30, 2017.

[29] M. Cupiał, A. Szeląg-Sikora, and M. Niemiec, "Optimisation of the Machinery Park with the Use of OTR-7 Software in Context of Sustainable Agriculture," Agric. Agric. Sci. Procedia, vol. 7, pp. 64-69, 2015.

[30] T. Lapczynska-Kordon, B; Fraczek, J; Slipek, Z; Ivanowa, "Genetic Algorithms In Optimisation Of Dried Fruits And Vegetables Quality," in Engineering for Rural Development, 2013, pp. 628-632 